OPEN ACCESS

Edited by:

S. Sridhar

Robert Bosch Centre for

Cyber-Physical Systems, Indian

Institute of Science, India

Reviewed by:

Fei Geng,

McMaster University, Canada Alok Ranjan Nayak,

International Institute of Information

Technology, India

${ }^{*}$ Correspondence:

Daisuke Sato

dsato@ucdavis.edu

${ }^{\dagger}$ Present Address:

Seunghyun Kim,

Department of Mathematics, University of California, Los Angeles,

Los Angeles, CA, United States

Specialty section:

This article was submitted to

Biomedical Physics,

a section of the journa

Frontiers in Physics

Received: 16 January 2018 Accepted: 20 September 2018

Published: 12 October 2018

Citation:

Kim S and Sato D (2018)

Mathematical Analysis of the Role

of Heterogeneous Distribution of

Excitable and Non-excitable Cells on

Early Afterdepolarizations.

Front. Phys. 6:117.

doi: 10.3389/fphy.2018.00117

\section{Mathematical Analysis of the Role of Heterogeneous Distribution of Excitable and Non-excitable Cells on Early Afterdepolarizations}

\author{
Seunghyun $\mathrm{Kim}^{1+}$ and Daisuke Sato ${ }^{2 *}$ \\ ${ }^{1}$ Department of Mathematics, University of California, Davis, Davis, CA, United States, ${ }^{2}$ Department of Pharmacology, \\ University of California, Davis, Davis, CA, United States
}

Early afterdepolarizations (EADs) are abnormal oscillations during the plateau phase of the cardiac action potential and have been linked to cardiac arrhythmias. At the cellular level, EADs can be caused by reactivation of the L-type calcium $\left(\mathrm{Ca}^{2+}\right)$ channels, spontaneous $\mathrm{Ca}^{2+}$ releases from the sarcoplasmic reticulum, or both. In tissue, these EADs can trigger action potentials in neighboring cells, which may propagate as a nonlinear wave. In this scenario, EADs are attributed to cellular/subcellular/channel properties. In this study, we show a novel mechanism of EADs due to heterogeneous distribution of excitable and non-excitable cells in tissue, using a physiologically detailed computational model and mathematical analysis. In tissue, excitability of cells depends on the cell type and physiological and pathological conditions. Non-excitable cells create a non-excitable gap in tissue, which has been thought to be a cause of slow waves and reflected waves. Here, we show that the non-excitable gap also can be responsible for EAD generation. However, EADs occur only when the non-excitable gap size is optimal. If the gap size is too small, no EADs occur. If the gap size is too large, the action potential wave cannot propagate through the gap region. We also demonstrate that EADs caused by the non-excitable gap can initiate reentry in tissue, which has been linked to ventricular tachycardia and fibrillation. Thus, the non-excitable gap can lead to both focal and reentrant arrhythmias. EADs shown in this study are spatial phenomena and require tissue heterogeneity. Our study sheds light on the role of tissue heterogeneity on focal and reentrant arrhythmias.

Keywords: early afterdepolarizations, heterogeneity, reflection, excitable media, reentry, arrhythmias, nonexcitable gap, cardiac tissue

\section{INTRODUCTION}

Sudden cardiac death is one of the major causes of death in the world [1]. Sudden cardiac death is most often caused by arrhythmias. Under normal conditions, action potential waves propagate smoothly in the heart. During arrhythmias, in contrast, action potential waves are less organized and often show spatiotemporally chaotic behaviors. However, it is not clear how regular sinus rhythm becomes irregular arrhythmias. 
Cardiac myocytes are excitable cells. These cells are coupled by gap junctions in tissue. The membrane excitability and gap junction coupling are highly heterogeneous in the heart $[2,3]$. These heterogeneities are especially amplified under pathological conditions such as heart failure and myocardial infarction [4-9].

Early afterdepolarizations (EADs) are abnormal oscillations of the membrane potential during the plateau phase of the action potential. EADs can be caused by reactivation of the $\mathrm{Ca}^{2+}$ and/or $\mathrm{Na}^{+}$channels or spontaneous $\mathrm{Ca}^{2+}$ releases from the sarcoplasmic reticulum, or both [10-15]. These abnormal oscillations can re-excite surrounding tissue and cause triggered activities if they overcome the source-sink mismatch [16-20].

Cardiac myocytes are electrotonically coupled via gap junctions in tissue. When some cells are excited in tissue, currents flow from excited cells to neighboring cells via gap junctions and excite the neighboring cells. The propagation excitation forms the action potential wave. Under pathological conditions such as ischemia and myocardial infarction, cells can be less excitable or non-excitable $[21,22]$. If one cell is non-excitable, the membrane potential of the cell is passively changed by the membrane potential of surrounding cells. Generally, one or few non-excitable cells do not cause a problem since the action potential wave can pass through these cells. However, as the number of non-excitable cells increases, the action potential wave slows down in this region, and eventually fails to propagate when the number of non-excitable cells exceeds a certain threshold. In addition to propagation failure, non-excitable cells in tissue also can cause retrograde waves, which may lead to focal arrhythmias. This phenomenon is known as "reflection" and shown in experiments using the ventricular tissue, atrial tissue, and Purkinje fiber [23-29]. These reflected waves have been also shown in computer simulations [30-35]. The simplified mathematical model of cardiac tissue showed the mechanisms of reflected waves and the role of the non-excitable region [31]. The detailed analysis using 1- and 2-variable models has shown that the number of reflected waves is highly sensitive to the size of the non-excitable region $[33,35]$.

In this study, we show how non-excitable cells in excitable tissue affect EAD formation due to reactivation of the $\mathrm{Ca}^{2+}$ channels using computational models and mathematical analysis. The key finding in this study is that a small region $(1 \sim 2 \mathrm{~mm})$ of non-excitable tissue can lead to EADs and promote arrhythmias. Thus, tissue properties are critical for EAD formation as well as cellular properties. Such heterogeneous distribution of nonexcitable and excitable cells in tissue, as in pathological conditions such as ischemia, can lead to the onset of ventricular tachycardia and fibrillation.

\section{MATERIALS AND METHODS}

\section{Physiological Model}

We used a physiologically detailed model of the rabbit ventricular action potential model used in our previous studies [19, 36-38]. The membrane potential is governed by

$$
\frac{\partial V(x, t)}{\partial t}=-s(x) \cdot \frac{I_{\text {ion }}(x, t)}{C_{m}}+\nabla \cdot D \nabla V(x, t),
$$

where $V$ is the membrane potential, $I_{i o n}$ is the total transmembrane current, $C_{m}$ is the cell membrane capacitance, $D$ is the effective diffusion constant of the voltage due to currents from neighboring cells through gap junctions, $x$ represents position in space and $t$ is time. In this study, we introduced the variable $s(x)$ to control excitability in tissue as follows (Figure 1A).

$$
\left\{\begin{array}{l}
s(x)=0 \text { for non }- \text { excitable cells } \\
s(x)=1 \quad \text { for excitable cells }
\end{array}\right.
$$

Since the original parameters of this model were built based on the healthy rabbit cell data [37], EADs do not occur even at slow heart rates. In order to promote EAD formation at the cellular level, we modified parameters to reduce repolarization reserve by increasing inward current $\left(\mathrm{I}_{\mathrm{CaL}}\right)$ and reducing $\mathrm{K}$ currents. We note that even with these modifications, EADs do not occur without the non-excitable gap. EADs occur only when the nonexcitable gap is inserted in tissue and/or repolarization reserve is further reduced by increasing $\mathrm{I}_{\mathrm{CaL}}$ (or decreasing $\mathrm{K}$ current). Parameters and equations used in this study are shown in the Supplementary Material.

\section{Computer Simulation}

A one-dimensional cable $(9 \mathrm{~cm})$ was paced at one end. To ensure propagation, the leftmost five cells were paced in a one-dimensional cable. Non-excitable cells were inserted in the middle of the cable as shown in Figure 1A. The two-dimensional

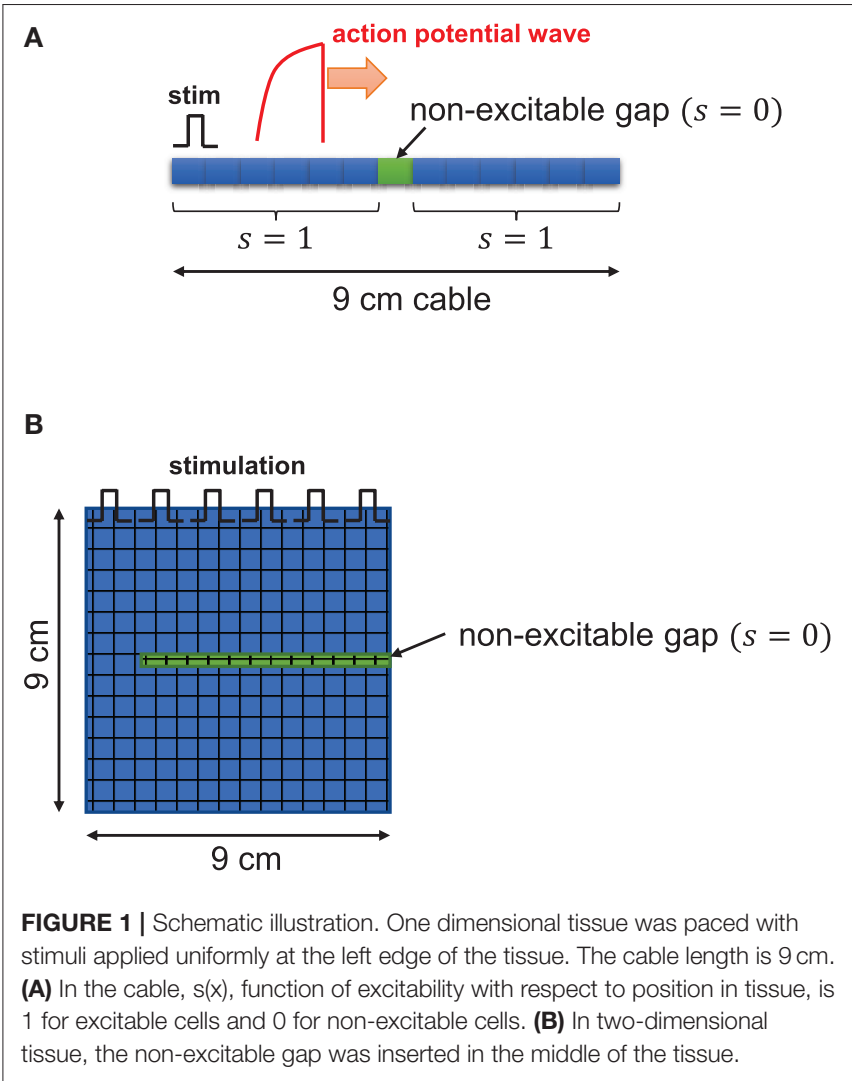


A

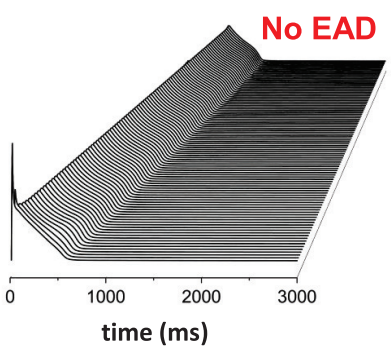

C
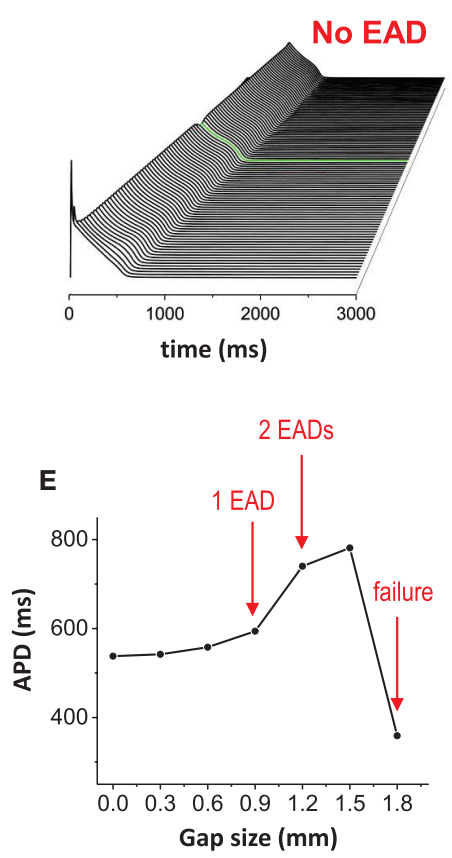

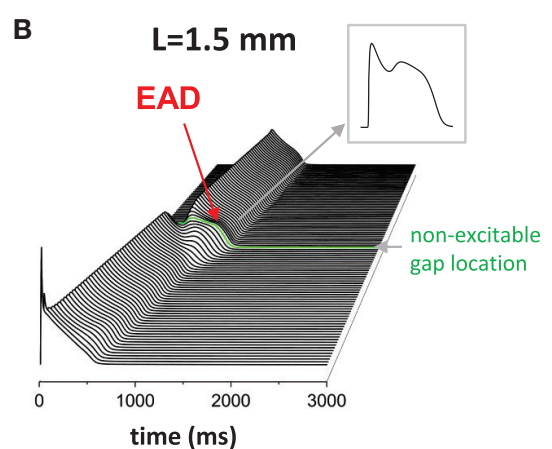

D

$\mathrm{L}=1.8 \mathrm{~mm}$

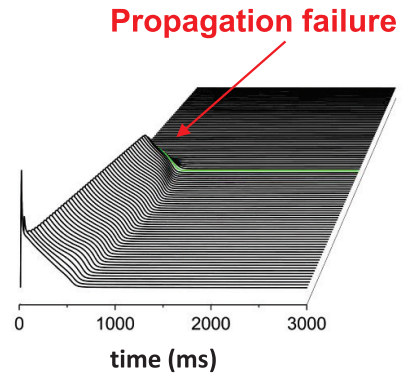

$\mathbf{F}$

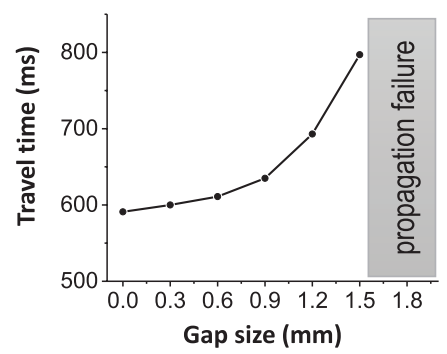

FIGURE 2 | Non-excitable gap causes EADs. (A) Without non-excitable gap, the action potential wave propagates without causing EADs in 1D tissue. Space-time plot. (B) When non-excitable gap is inserted, EADs occurred around the non-excitable gap region. The maximum APD is $781 \mathrm{~ms}$. The gap size is $1.5 \mathrm{~mm}$. (C) If the gap size is too small $(0.6 \mathrm{~mm})$, no EADs occurred. (D) If the gap size is too large $(1.8 \mathrm{~mm})$, propagation failed at the gap region. (E) APD vs. the gap size. (F) The travel time of action potential wave vs. gap size.

tissue $(9 \times 9 \mathrm{~cm})$ was paced from the top and non-excitable cells were inserted as shown in Figure 1B. We solve this equation using the operator splitting method [39]. We use the Euler method with the variable time step of $0.01 \sim 0.1 \mathrm{~ms}$ to compute the single cell action potential. The space step $(\Delta x)$ is $150 \mu \mathrm{m}$, which is similar to the length of the cardiac myocyte. For the numerical accuracy, we used double precision in our simulations and checked the results using smaller time steps. All codes are written in $\mathrm{C} / \mathrm{C}++$. We used the 25-node high-performance computing cluster.

\section{Simplified Model}

In order to understand the dynamical mechanisms of EADs due to non-excitable gap, we also constructed the reduced mathematical model of EADs. The basic structure of the model is the same as our previous studies [40]. This model has three variables: membrane voltage $(v)$, and gating variables $(f$ and $x)$. These variables are governed by

$$
\begin{aligned}
C_{m} \frac{d v}{d t} & =-\left(i_{C a}+i_{K}\right)+g_{g a p}\left(v_{2}-v\right), \\
\frac{d f}{d t} & =\frac{f_{\infty}-f}{\tau_{f}}, \\
\frac{d x}{d t} & =\frac{x_{\infty}-x}{\tau_{x}},
\end{aligned}
$$

where $i_{C a}$ is the simplified L-type $\mathrm{Ca}^{2+}$ current and $i_{K}$ is the generic $\mathrm{K}$ current, $g_{g a p}$ is the effective conductance between 
A

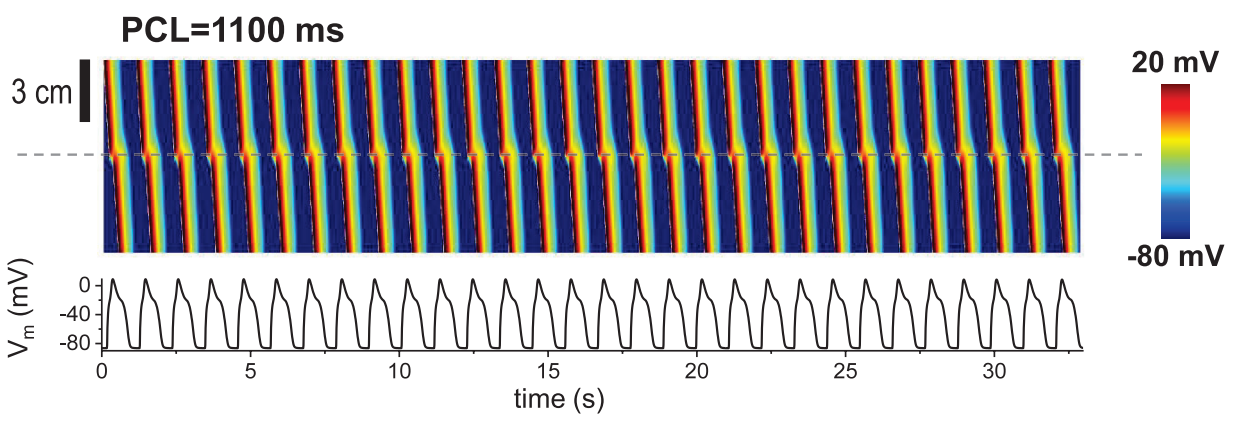

B
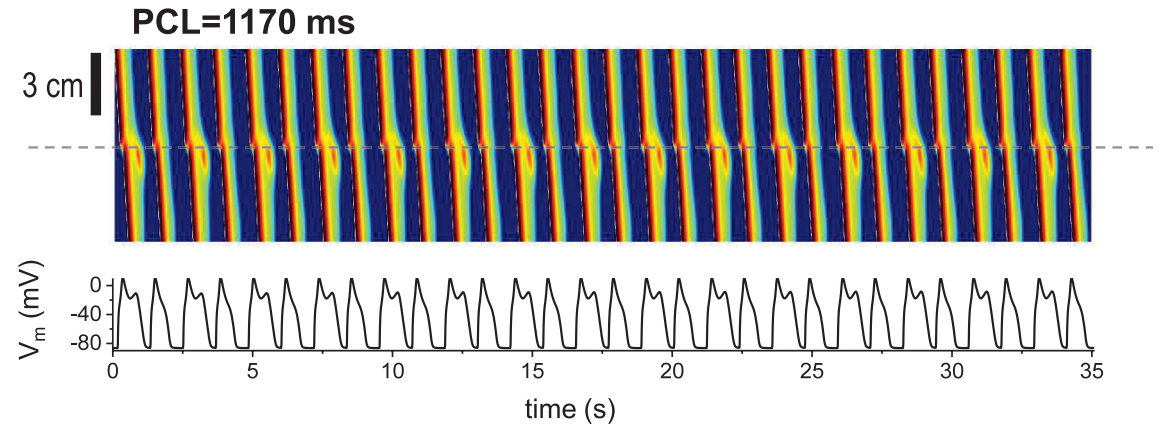

C

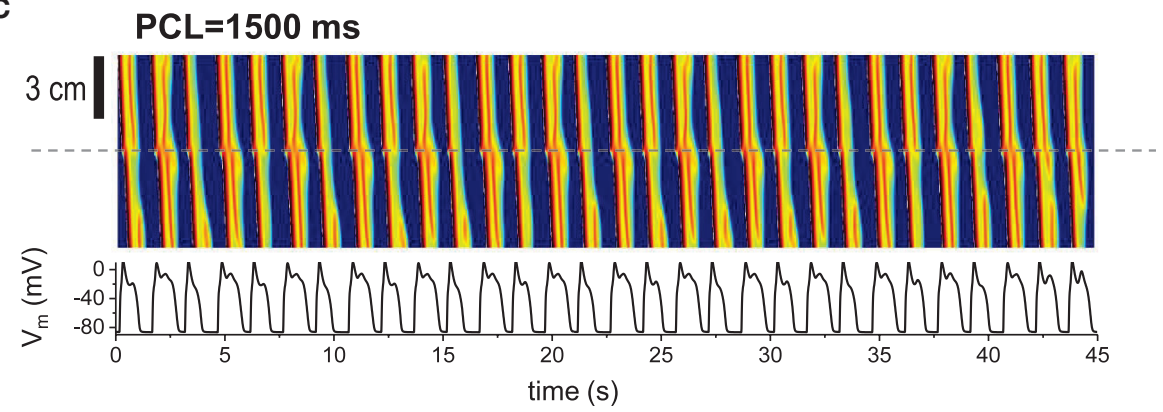

FIGURE 3 | Repetitive pacing When 1D cable was paced repetitively, various patterns appeared. Top: Space-time plot. The AP traces (bottom) were taken at the middle of the cable (indicated by dashed lines). The gap size is $1.5 \mathrm{~mm}$. The tissue was paced 200 times. Last 30 beats are shown here. (A) Periodic (period-1) pattern. No EADs at the gap region. (B) Period-2. EADs occur every other beat. (C) Complex pattern. Spatiotemporal chaos.

proximal and distal regions. $v_{2}$ is the membrane potential in the distal region. Due to the large delay at the gap region, the action potential in the distal region remains the plateau phase when the membrane potential in the proximal region is repolarizing. Thus, the membrane potential in the distal region was assumed to be constant. $f$ and $x$ are gating variables of the $\mathrm{Ca}^{2+}$ current and the generic K current, respectively. $f_{\infty}$ and $x_{\infty}$ are steady state values of $f$ and $x$ gates, respectively. $\tau_{f}$ and $\tau_{x}$ are time constants of $f$ and $x$ gates, respectively. The simplified L-type $\mathrm{Ca}^{2+}$ current and the generic K current are

$$
\begin{aligned}
i_{C a} & =g_{C a} d_{\infty} f\left(v-e_{C a}\right), \\
i_{K} & =g_{k} \cdot x \cdot\left(v-e_{k}\right),
\end{aligned}
$$

where $g_{C a}$ is the maximum conductance of $i_{C a}, g_{k}$ is the maximum conductance of $i_{k}, d_{\infty}$ is the instantaneous activation gate of the $\mathrm{Ca}^{2+}$ channel, $e_{\mathrm{Ca}}$ is the reversal potential of $i_{C a}, e_{k}$ is the reversal potential of $i_{k}$. Steady state values, $d_{\infty}, f_{\infty}$ and $x_{\infty}$ are voltage dependent and governed by

$$
\begin{aligned}
& d_{\infty}=\frac{1}{1+\exp \left(-\frac{v+32}{6.24}\right)}, \\
& f_{\infty}=\frac{1}{1+\exp \left(\frac{v+21}{8.6}\right)}, \\
& x_{\infty}=\frac{1}{1+\exp \left(-\frac{v+35}{5}\right)} .
\end{aligned}
$$

We use the Euler method with the variable time step of $0.1 \mathrm{~ms}$ to solve the simplified model.

\section{RESULTS}

One-dimensional cable was paced at one end. In this study, the cable length is $9 \mathrm{~cm}$, which is longer than the typical human 


\section{A}

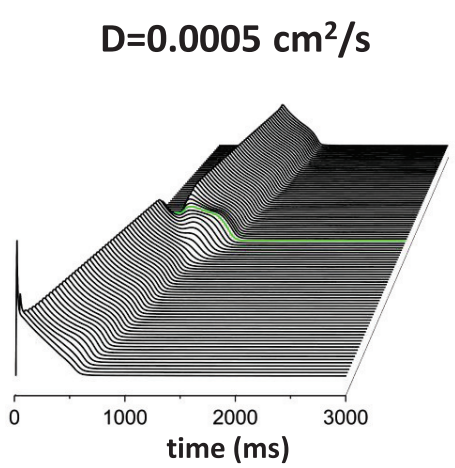

C

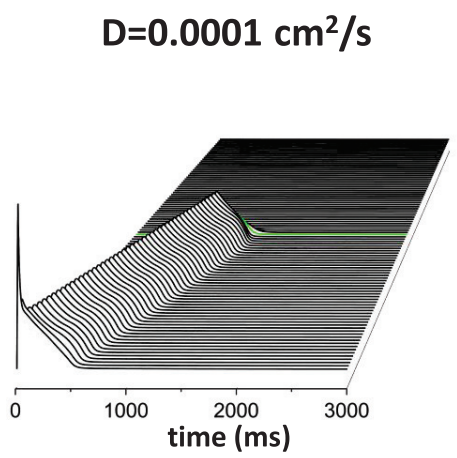

B

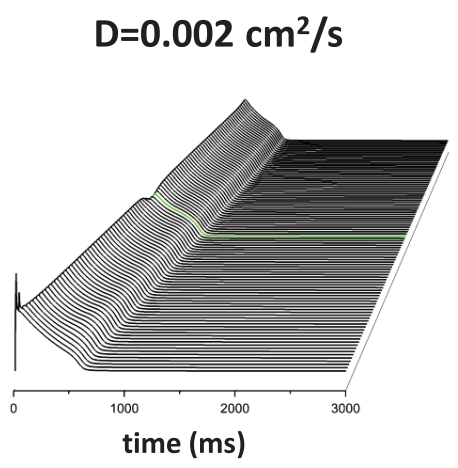

D

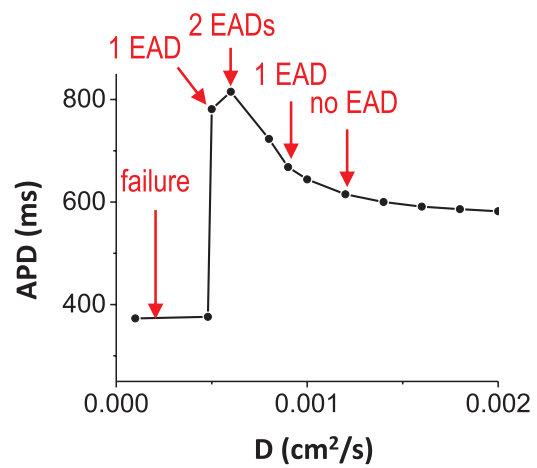

FIGURE 4 | Gap junction conductance affects EAD formation. The diffusive current between cells also affects EAD formation. In this figure, the gap size was fixed at $1.5 \mathrm{~mm}$. (A) normal D. $D=0.0005 \mathrm{~cm}^{2} / \mathrm{s}$. (B) large $D . D=0.002 \mathrm{~cm}^{2} / \mathrm{s}$. (C) small $\mathrm{D}$. $\mathrm{D}=0.00001 \mathrm{~cm}^{2} / \mathrm{s}$. (D) APD vs. $D$.

heart size, to avoid unnecessary boundary effects. When cells are well connected via gap junctions without a non-excitable gap, the action potential wave propagates smoothly without EADs in the cable (Figure 2A). Hereafter, we refer to this case as the "control" case. The maximum action potential duration (APD) in the cable was $538 \mathrm{~ms}$ in the control case. The travel time of the action potential wave from one end to the other end totaling $9 \mathrm{~cm}$ was $591 \mathrm{~ms}$. When a non-excitable gap of $1.5 \mathrm{~mm}(=10$ cells $)$ is inserted in the middle of the cable (Figures 1, $2 \mathrm{~B}$ green line), the propagation speed of the action potential slows down at the gap region. In this case, the travel time of the action potential wave propagated from one end to the other end was $797 \mathrm{~ms}$. Therefore, the delay of the propagation at the gap region is $259 \mathrm{~ms}$. In addition, EADs occur near the gap region (Figure 2B). In this case, the maximum APD in the cable was $781 \mathrm{~ms}$. The gap size is critical for the formation of EADs. If the gap size is too small, EADs do not occur (Figure 2C). EADs occurred only when the gap size reaches $1.5 \mathrm{~mm}$. On the other hand, if the gap size is too large (gap size greater than or equal to $1.8 \mathrm{~mm}$ ), the action potential wave cannot propagate due to non-excitability in the gap (Figure 2D). Figure 2E shows a graph of APD vs. gap size, and the number of EADs with different gap sizes. Additionally, the travel time of action potential wave is depicted against the gap size (Figure 2F). Note that the action potential fails to propagate if the gap size is larger than $1.8 \mathrm{~mm}$.
In our previous studies, we have shown that EADs can be periodic and chaotic due to nonlinearity of EAD dynamics [15, $19,40-42]$. When the 1D cable was paced repetitively, various patterns appeared such as periodic (period-1), period-2 and even spatiotemporally chaotic patterns (Figures $3 \mathrm{~A}-\mathrm{C}$ ). These patterns appear only when non-excitable cells exist in tissue.

When the non-excitable gap exists, changing the gap junction conductance also has the similar effects to the gap size since the effective gap size is proportional to $1 / \sqrt{ } D$. In other words, the diffusion coefficient $D$ rescales the length of the gap. Thus, although changing the size and changing the gap junction conductance are physiologically different, mathematically, we expect similar results. We used a fixed gap size $=1.5 \mathrm{~mm}$ for all simulations in Figure 4. When $D$ is normal value $(D=0.0005$ $\mathrm{cm}^{2} / \mathrm{s}$ ), 1 EAD was observed near the gap region (Figure 4A). If $D$ becomes larger $\left(D=0.002 \mathrm{~cm}^{2} / \mathrm{s}\right)$, the effective gap size becomes smaller and no EADs occurred (Figure 4B). If $D$ is too small ( $D$ $=0.00001 \mathrm{~cm}^{2} / \mathrm{s}$ ), the action potential wave could not cross the gap region due to the large effective gap (Figure 4C). Figure 4D shows how diffusive coupling impacts EAD formation. There is an optimal window for EAD formation.

Reducing repolarization reserve by increasing inward currents such as $I_{\mathrm{CaL}}$ and/or reducing outward currents such as $I_{\mathrm{Kr}}$ and $I_{\mathrm{Ks}}$, promotes EAD generation. When $I_{\mathrm{CaL}}$ is increased (Figure 5A), APD was prolonged $(\mathrm{APD}=1816 \mathrm{~ms})$ and the 
A

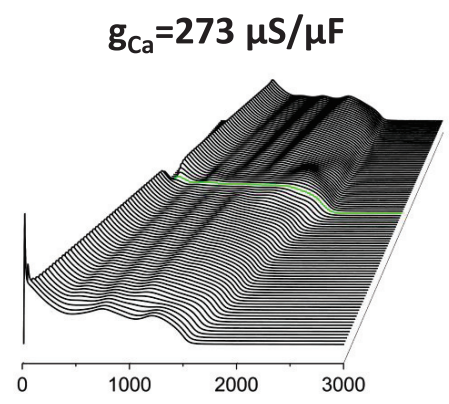

time (ms)

C

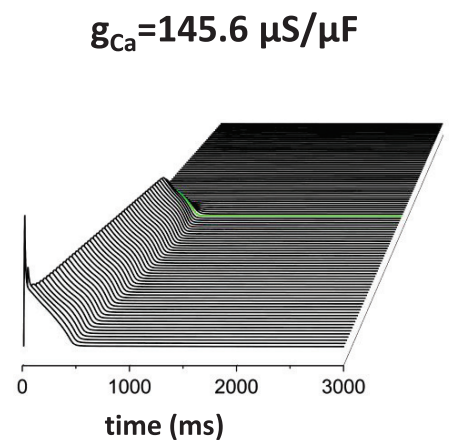

B $\mathrm{g}_{\mathrm{Ca}}=182 \mu \mathrm{S} / \mu \mathrm{F}$
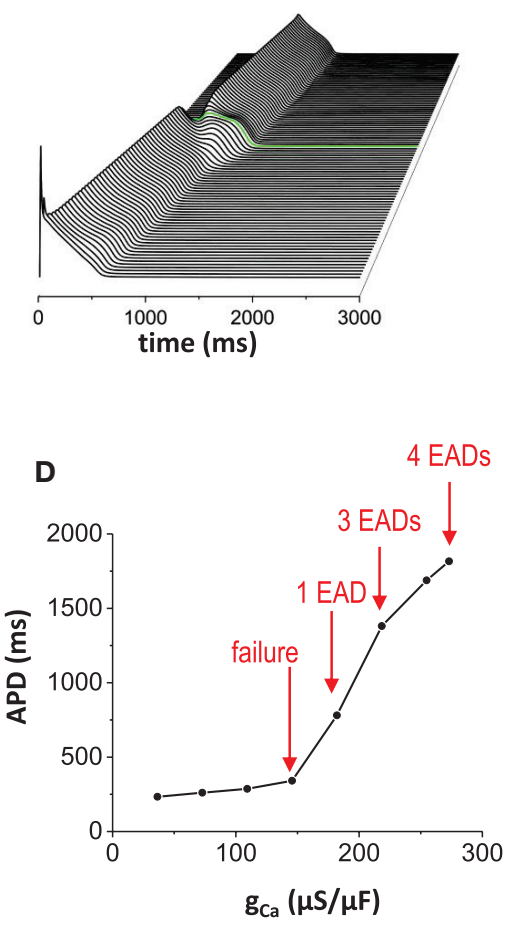

FIGURE 5 | Effects of the inward current. When inward current $\left(I_{\mathrm{CaL}}\right)$ is increased, EADs occur without the non-excitable gap region. In addition, non-excitable gap promotes EADs further (A). $g_{\mathrm{Ca}}=273 \mu \mathrm{A} / \mu \mathrm{F}$. Without the non-excitable gap region, 3 EADs were observed. Near the gap region, 4 EADs were observed. The maximum APD is $1816 \mathrm{~ms}$. (B) $g_{\mathrm{Ca}}=182 \mu \mathrm{A} / \mu \mathrm{F}$. Control. The maximum APD is $781 \mathrm{~ms}$. (C) $g_{\mathrm{Ca}}=145.6 \mu \mathrm{A} / \mu \mathrm{F}$. The maximum APD is $341 \mathrm{~ms}$. (D) a graph of APD vs. $g_{\mathrm{Ca}}$.

action potential wave has EADs without the non-excitable gap. When the non-excitable gap is inserted, it promoted EADs further if the gap size optimal (the gap size is $1.5 \mathrm{~mm}$ in Figure 5). Near the gap region, four EADs occurred whereas only three EADs occurred in the other regions. Figure 5B is the control model for comparison. If the inward current is too small, the action potential is too short to provide enough source current to initiate new action potential in the distal region even if the gap size is optimal for the control model (Figure 5C). Figure 5D is a graph of APD vs. conductance of the inward current $\left(\mathrm{g}_{\mathrm{Ca}}\right)$, summarizing our observation that EADs occur when the inward current increases.

Reducing outward current also has the same effects (Figures 6A-D). When the outward current became smaller (in this case, we reduced $I_{\mathrm{NaK}}$ ), more EADs occurred (Figure 6A). Figure $6 \mathrm{~B}$ is the control model for comparison. Then, when the outward current became too large, the action potential wave failed to propagate (Figure 6C). To summarize these results, we plotted a graph of APD against conductance of the outward current ( $\mathrm{g}_{\mathrm{NaK}}$; Figure 6D).

To understand the dynamical mechanisms of EADs due to the non-excitable gap, we analyzed using a simplified mathematical model of EADs (see Material and Methods). In this model, $v$ is the membrane potential of the cell in the proximal region near the gap. We assessed how current from the distal region promotes EAD generation. We assume the membrane potential of the cell in the distal region $\left(v_{2}\right)$ remains in the plateau phase due to the large delay (>200 ms) of the propagation at the gap region. Since $x$ is the slowest variable in this system, we take it as a parameter. Then, the 2-variable system can be written as

$$
\begin{aligned}
\frac{d v}{d t}=F(v, f) & =-\left(g_{C a} d_{\infty} f\left(v-e_{C a}\right)+g_{k} \cdot x \cdot\left(v-e_{k}\right)\right) \\
& +g_{g a p}\left(v_{2}-v\right) \\
\frac{d f}{d t}=G(v, f) & =\frac{f_{\infty}-f}{\tau_{f}}
\end{aligned}
$$

where

$$
\begin{aligned}
& d_{\infty}=\frac{1}{1+\exp \left(-\frac{v+32}{6.24}\right)} \\
& f_{\infty}=\frac{1}{1+\exp \left(\frac{v+21}{8.6}\right)}
\end{aligned}
$$


A

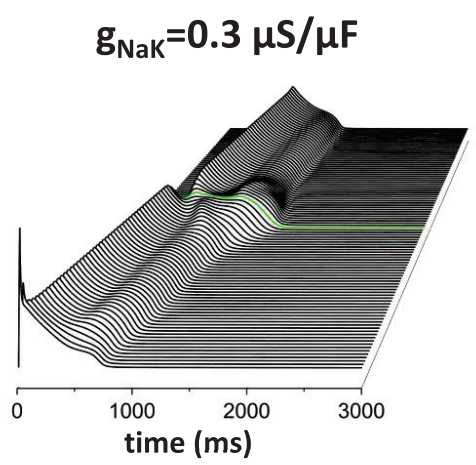

C

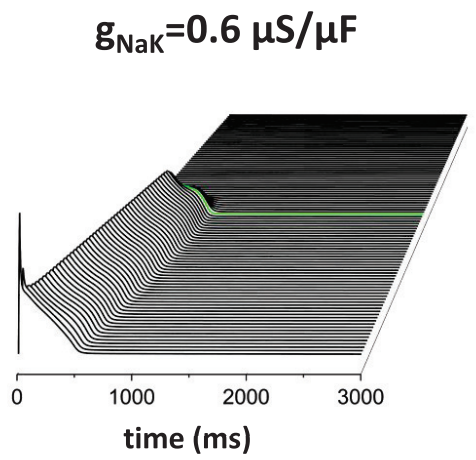

B
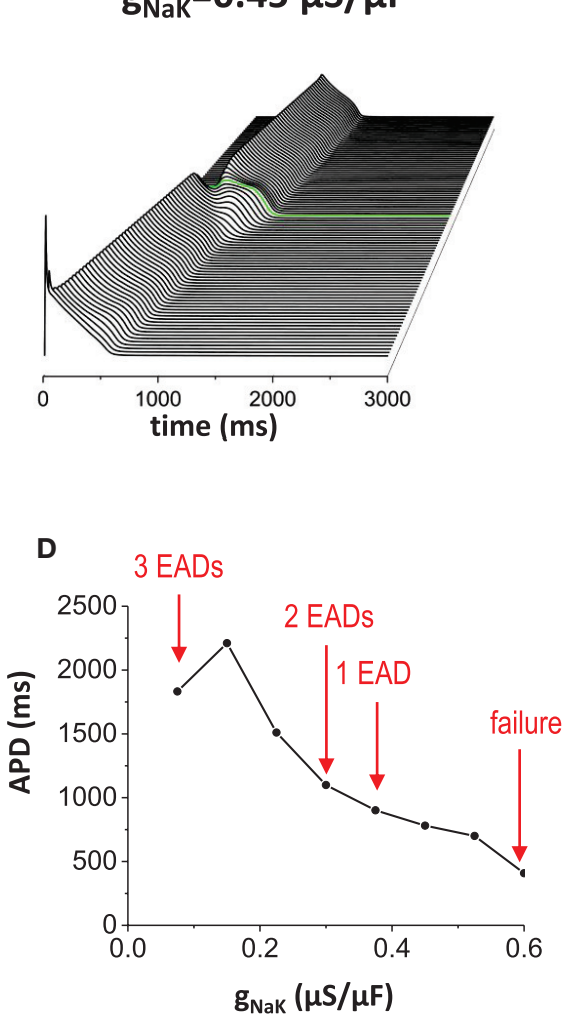

FIGURE 6 | Effects of the outward current. Reducing outward current ( $\left.I_{\text {NaK }}\right)$ also has similar effects of increasing inward current. (A) When the outward current was reduced $(g \mathrm{NaK}=0.3 \mu \mathrm{A} / \mu \mathrm{F})$, EADs occured without the non-excitable gap region. Near the gap region, more EADs were observed $(2 \mathrm{EADs})$. (B) $g \mathrm{NaK}=0.45 \mu \mathrm{A} / \mu \mathrm{F}$. Control. (C) $g_{\mathrm{NaK}}=0.6 \mu \mathrm{A} / \mu \mathrm{F}$. Large outward current reduces APD. Since APD is shorter, the action potential in the proximal region cannot provide enough source current to excite cells in the distal region. (D) APD vs. $g_{\text {NaK }}$.

Thus, the matrix to compute the stability of the system is

$$
\begin{aligned}
M & =\left(\begin{array}{ll}
F_{v} & F_{f} \\
G_{v} & G_{f}
\end{array}\right) \\
& =\left(\begin{array}{cc}
-g_{C a} d_{\infty}^{\prime} f v-g_{C a} d_{\infty} f-g_{k} x+g_{g a p} & -g_{C a} d_{\infty} v \\
f_{\infty}^{\prime} / \tau_{f} & -1 / \tau_{f}
\end{array}\right)
\end{aligned}
$$

Figures 7A-C show the effects of the current from the distal region. As the gap junction conductance is increased (from $g_{\text {gap }}=0$ to $g_{\text {gap }}=0.009 \mu \mathrm{A} / \mu \mathrm{F}$ ), the attractor region (blue part in Figure 7A) was extended and repeller (green part in Figure 7A) became attractor (unstable focus $\rightarrow$ stable focus). We varied the distal membrane potential from $+30 \mathrm{mV}$ to $-30 \mathrm{mV}$ (Figures 7B,C). In all cases, the current from the distal region promoted oscillatory attractors. We note that if the distal membrane potential becomes lower than $\sim-30 \mathrm{mV}$, the current from the distal region suppresses EADs. We also computed basins of attraction (Figures 7D-F). In all cases, the basin of attraction was increased as the gap junction conductance was increased. However, as the distal membrane potential becomes lower, larger conductance was required to extend the basin of attraction (Figure 7E vs. Figure 7F). On the other hand, the current from the distal region has little effect on fix points (red dots in Figure 7) and EAD oscillations always occur near $-20 \mathrm{mV}$.

When non-excitable cells are inserted in 2-dimensional tissue, EADs caused by the non-excitable gap region can initiate reentry, which has been associated with ventricular tachycardia. Without non-excitable gap, the action potential wave propagates smoothly. When non-excitable gap is inserted (Figure 1C), EADs occur near this region. EADs prolong APD. Thus, if cells in this region cannot recover by the time the next wave arrives, the wave cannot propagate in this region. This large dispersion of refractoriness and regional block of the wave can cause reentry (Figure 8A, Supplemental Movie 1). If the gap size is too small to cause EADs, although there is a small delay of the propagation at the gap region, dispersion of refractoriness is much smaller and rarely causes reentry (Figure 8B, Supplemental Movie 2). If the gap size is too large, any waves cannot propagate in this region and waves go around this region (Figure 8C, Supplemental Movie 3). These results demonstrate that non-excitability in tissue can lead to large dispersion of refractoriness and may cause arrhythmias. 

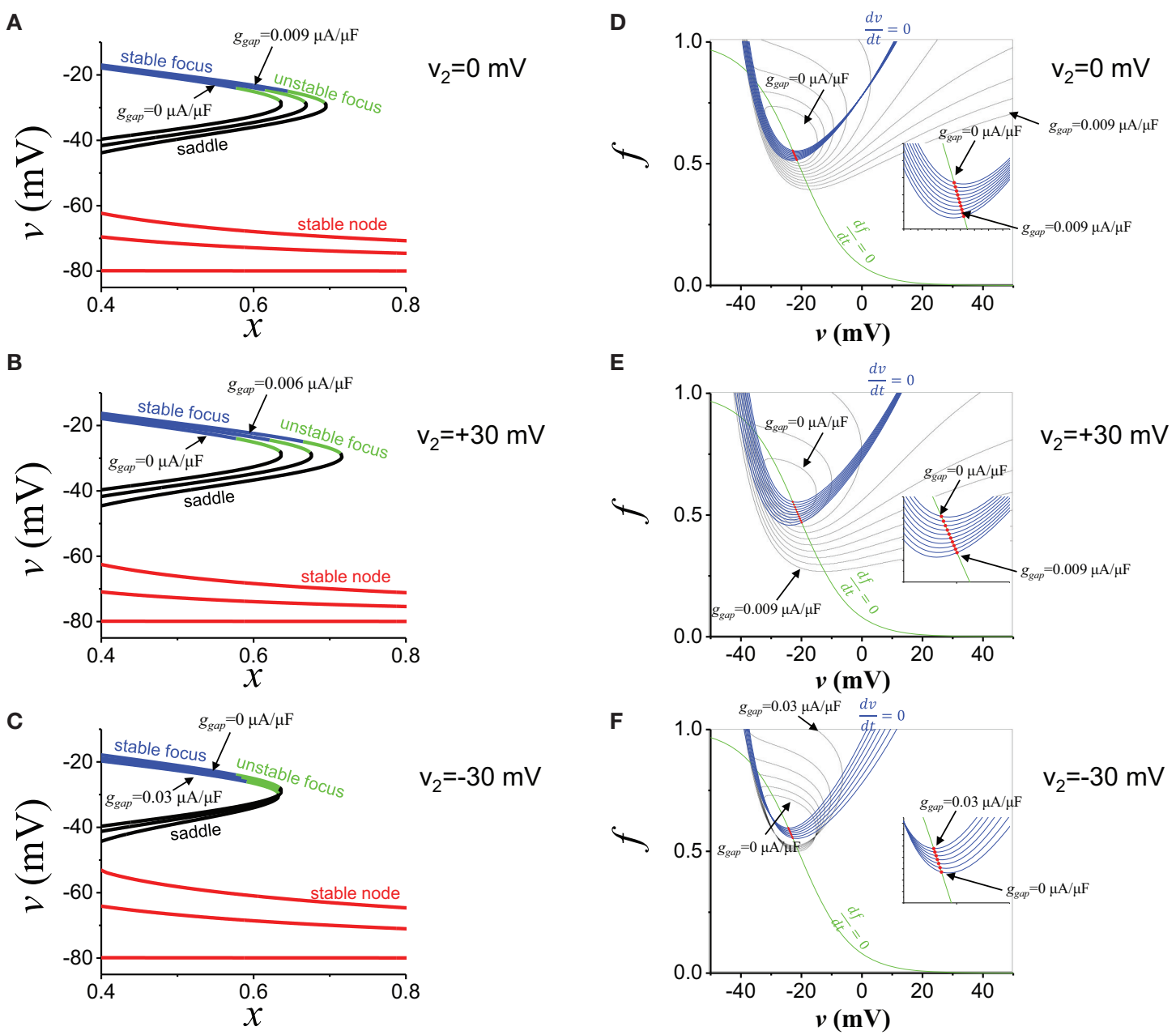

FIGURE 7 | EAD mechanisms. (A) The stability of the fats subsystem $(v, f) . x$ is the parameter. Blue: stable focus. Green: unstable focus. Black: saddle. Red: stable node. Ggap values are $0,0.0045$, and $0.009 \mu \mathrm{A} / \mu \mathrm{F} . v_{2}$ is $0 \mathrm{mV}$. (B) The same as (A), but $v_{2}$ is $+30 \mathrm{mV}$. ggap values are 0, 0.003 , and $0.006 \mu \mathrm{A} / \mu \mathrm{F}$. (C) The same as (A), but $v_{2}$ is $-30 \mathrm{mV}$. ggap values are 0, 0.015, and $0.03 \mu \mathrm{A} / \mu \mathrm{F}$. (D) Basin of attraction. ggap value was varied from 0 to $0.009 \mu \mathrm{A} / \mu \mathrm{F}$. $v_{2}$ is $0 \mathrm{mV}$. Red dots indicate fixed points. Blue and green lines are nuclines. (E) The same as (D), but $v_{2}$ is $+30 \mathrm{mV}$. ggap value was varied from 0 to $0.009 \mu \mathrm{A} / \mu \mathrm{F}$. (F) The same as (D), but $v_{2}$ is $-30 \mathrm{mV}$. ggap value was varied from 0 to $0.03 \mu \mathrm{A} / \mu \mathrm{F}$.

\section{DISCUSSION}

Tissue heterogeneity has been thought to be one of the contributing factors of arrhythmias [43-47]. In this study, we investigated how non-excitable cells in excitable tissue promote EADs and thus arrhythmias.

EADs can be caused by reactivation of the $\mathrm{Ca}^{2+}$ channels, spontaneous $\mathrm{Ca}^{2+}$ releases from the SR, or both [10-15]. In addition, recent studies have shown that reactivation of the $\mathrm{Na}^{+}$channels can also lead to EADs [15, 48]. In this study, we showed the mechanism of $\mathrm{Ca}^{2+}$ channel-mediated EADs due to heterogeneously distributed excitable and non-excitable cells, and demonstrated reentrant arrhythmias in 2D tissue using physiologically detailed computational models. It has been wellstudied how non-excitable cells in excitable tissue can lead to reflected waves [23-29]. In these studies, the key to the reflected waves was reactivation of the $\mathrm{Na}^{+}$channels. In this study, we showed the reflection occurs at the plateau voltage due to reactivation of the $\mathrm{Ca}^{2+}$ channels. In our simulations, EADs did not cause a retrograde wave since the amplitude of EADs was too small but prolonged APDs.

The number of EADs is sensitive to the gap size (Figure 2). The detailed analysis using a two-variable model has shown that there are infinite patterns of reflected waves $(1$ reflected wave, 2 reflected waves, 3 reflected waves ... infinite reflected waves) between normal propagation (no reflected waves) and propagation failure when the gap size is varied [33]. In our study, we did not observe these patterns even when the gap size is finely tuned. This is probably because the memory effect in the model interfered the patterns. 


\section{A}
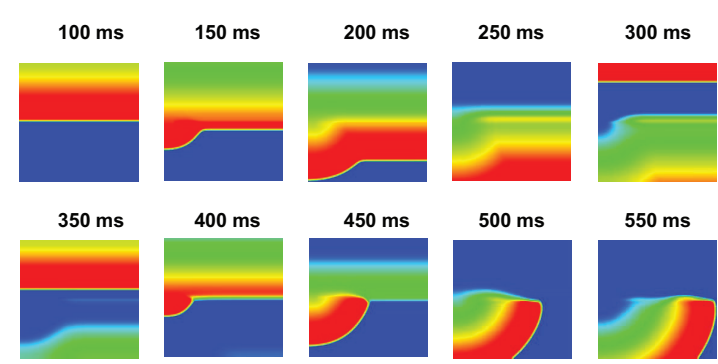

$550 \mathrm{~ms}$

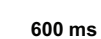

$650 \mathrm{~ms}$

$700 \mathrm{~ms}$
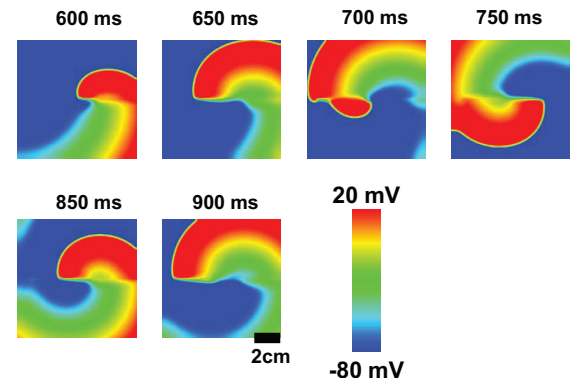

B
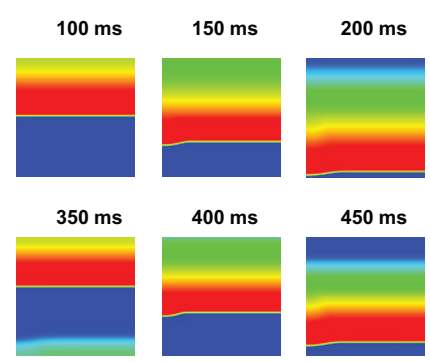

C
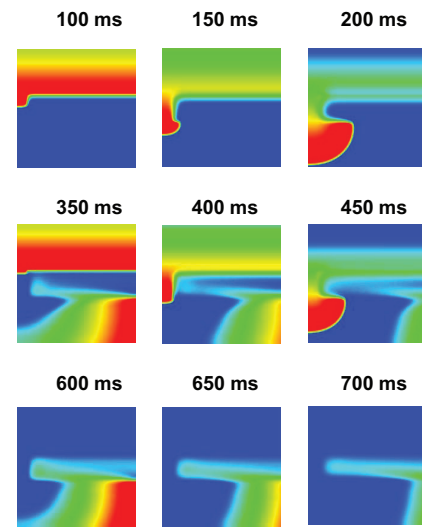
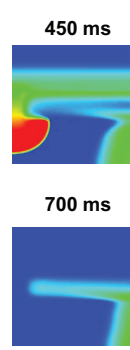
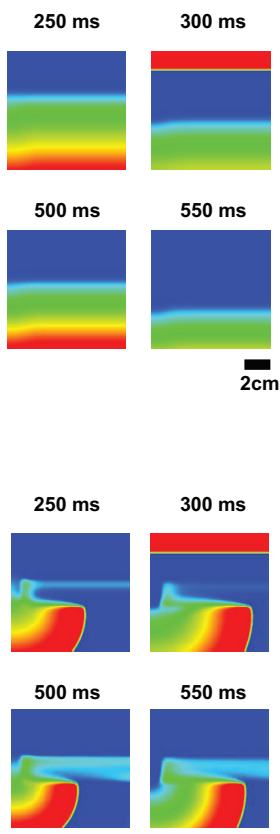

$550 \mathrm{~ms}$

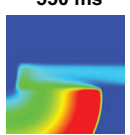

$750 \mathrm{~ms}$

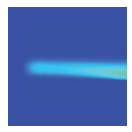

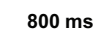

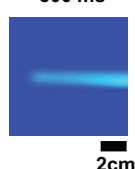

FIGURE 8 | EADs due to the non-excitable gap region cause reentry. (A) The optimal non-excitable gap region $(1.2 \mathrm{~mm}$ ) cause EADs. These EADs block the next action potential wave and cause reentry. The tissue size is $9 \times 9 \mathrm{~cm}$.

(Supplemental Movie 1; B) If the gap size is too small, EADs will not occur although there is a delay at the gap region. (Supplemental Movie 2; C) If the gap size is too large, the action potential wave cannot propagate and the wave avoids this region (Supplemental Movie 3).
In tissue, large dispersion of refractoriness can initiate reentry [49]. When non-excitable cells are inserted in 2D tissue, dispersion of refractoriness can be observed without EADs (Figure 8B, Supplemental Movie 2). However, the dispersion is small in this case. When EADs occur, the dispersion becomes large enough to initiate reentry (Figure $\mathbf{8 A}$, Supplemental Movie 1). The non-excitable gap also becomes an anchor of the spiral waves (Supplemental Movie 1). But no EADs were observed since the cycle of the rotation of the spiral wave was too fast for EADs. If the gap size is too large, the gap region blocks action potential waves (Figure 8C, Supplemental Movie 3). It is known that obstacles in tissue can lead to reentry $[50,51]$. Thus, the large gap region can also initiate reentry by different mechanisms.

It is known that tissue geometry is also an important factor for reflected waves [32]. When an action potential wave propagates from a narrow path to a wide path, the propagation speed slows down due to the source-sink mismatch. This delay can re-excite the cells in the narrow path and cause a retrograde wave. Thus, propagation delay due to tissue geometry may be able to initiate EADs. This possibility needs to be investigated.

Reflected waves have been observed and investigated in various systems such as cardiac tissue and neurons. The cardiac subcellular $\mathrm{Ca}^{2+}$ system is also an excitable system. Under normal conditions, $\mathrm{Ca}^{2+}$ release from the sarcoplasmic reticulum (SR) forms a spark. However, when $\mathrm{Ca}^{2+}$ sparks recruit new $\mathrm{Ca}^{2+}$ sparks in neighboring $\mathrm{Ca}^{2+}$ release units, $\mathrm{Ca}^{2+}$ sparks propagate as a wave $[52,53]$. Each $\mathrm{Ca}^{2+}$ release unit contains a few to several hundred ryanodine receptors [54-58] and the number of ryanodine receptors affects the positive feedback process known as $\mathrm{Ca}^{2+}$-induced $\mathrm{Ca}^{2+}$ release $[58,59]$. In addition, the subcellular structure is very complex. These subcellular heterogeneities may lead to reflection and form complex patterns in $\mathrm{Ca}^{2+}$ waves.

In this paper, we showed only mathematical and computational results. These results should be verified in experiments. Reflected waves have been observed in many wet experiments. We expect that we can use the same experimental setup for EADs due to non-excitable cells. However, to observe EADs, repolarization reserve needs to be reduced.

\section{CONCLUSIONS}

Cellular mechanisms of EADs have been widely studied. In this study, we showed that tissue properties are also critical for initiation and promotion of EADs. Non-excitable gap in tissue can promote EADs and prolonged action potentials due to EADs can cause conduction block and reentry of the action potential wave.

The limitation of this study is that we considered only $\mathrm{Ca}^{2+}$ channel reactivation. Retrograde waves propagate when the $\mathrm{Na}^{+}$ channels are reactivated. If both cases are considered, focal and reentrant arrhythmias can coexist and the dynamics will become much more complex.

Ablation creates non-excitable tissue. The border zone of myocardial infarction is also mixture of 
excitable and non-excitable cells. Our study implies that EADs can be promoted in these regions due to tissue heterogeneity. This study sheds light on the role of tissue heterogeneity on EAD generation and initiation of reentrant arrhythmias.

\section{AUTHOR CONTRIBUTIONS}

All authors SK and DS contributed ideas and discussion. All authors performed computer simulations and mathematical analysis, wrote the manuscript, approved the final version of the manuscript and agree to be accountable for all aspects of the work.

\section{FUNDING}

This work was supported by National Institutes of Health grant R00-HL111334, American Heart Association Grant-in-Aid

\section{REFERENCES}

1. Zipes DP, Wellens HJJ. Sudden cardiac death. Circulation (1998) 98:2334-51.

2. Roberts-Thomson KC, Lau DH, Sanders P. The diagnosis and management of ventricular arrhythmias. Nat Rev Cardiol. (2011) 8:311-21. doi: 10.1038/nrcardio.2011.15

3. Burchfield JS, Xie M, Hill JA. Pathological ventricular remodeling: mechanisms: part 1 of 2. Circulation (2013) 128:388-400. doi: 10.1161/circulationaha.113.001878

4. Peters NS. Myocardial gap junction organization in ischemia and infarction. Microsc Res Tech. (1995) 31:375-86. doi: 10.1002/jemt.10703 10507

5. Saffitz JE, Schuessler RB, Yamada KA. Mechanisms of remodeling of gap junction distributions and the development of anatomic substrates of arrhythmias. Cardiovasc Res. (1999) 42:309-17.

6. Jongsma HJ, Wilders R. Gap junctions in cardiovascular disease. Circ Res. (2000) 86:1193-7. doi: 10.1161/01.RES.86.12.1193

7. Severs NJ. Gap junction remodeling in heart failure. J Card Fail (2002) 8:S293-9. doi: 10.1054/jcaf.2002.129255

8. Severs NJ, Coppen SR, Dupont E, Yeh HI, Ko YS, Matsushita T. Gap junction alterations in human cardiac disease. Cardiovasc Res. (2004) 62:368-77. doi: 10.1016/j.cardiores.2003.12.007

9. Bruce AF, Rothery S, Dupont E, Severs NJ. Gap junction remodelling in human heart failure is associated with increased interaction of connexin 43 with ZO-1. Cardiovas Res. (2008) 77:757-65. doi: 10.1093/cvr/cvm083

10. January C, Riddle J. Early afterdepolarizations: mechanism of induction and block. A role for L-type Ca2+ current. Circ Res. (1989) 64:977-90.

11. January CT, Moscucci A. Cellular mechanisms of early afterdepolarizationsa. Ann N Y Acad Sci. (1992) 644:23-32. doi: 10.1111/j.1749-6632.1992.tb30999.x

12. Zeng J, Rudy Y. Early afterdepolarizations in cardiac myocytes: mechanism and rate dependence. Biophys J. (1995) 68:949-64. doi: 10.1016/s0006-3495(95)80271-7

13. Viswanathan PC, Rudy Y. Pause induced early afterdepolarizations in the long QT syndrome: a simulation study. Cardiovas Res. (1999) 42:530-42. doi: 10.1016/s0008-6363(99)00035-8

14. Volders PGA, Vos MA, Szabo B, Sipido KR, de Groot SHM, Gorgels APM, et al. Progress in the understanding of cardiac early afterdepolarizations and torsades de pointes: time to revise current concepts. Cardiovas Res. (2000) 46:376-92. doi: 10.1016/s0008-6363(00)00022-5

15. Sato D, Clancy CE, Bers DM. Dynamics of sodium current mediated early afterdepolarizations. Heliyon (2017) 3:e00388. doi: 10.1016/j.heliyon.2017.e00388
16GRNT31300018, and Amazon AWS Cloud Credits for Research (DS).

\section{ACKNOWLEDGMENTS}

The authors wish to thank Dr. Timothy J. Lewis for a critical reading of the manuscript, and his comments and suggestions.

\section{SUPPLEMENTARY MATERIAL}

The Supplementary Material for this article can be found online at: https://www.frontiersin.org/articles/10.3389/fphy. 2018.00117/full\#supplementary-material

Supplemental Movie 1 | Movie of Figure 8A.

Supplemental Movie 2 | Movie of Figure 8B.

Supplemental Movie 3 | Movie of Figure 8C.

16. Gilmour RF, Moïse S. Triggered activity as a mechanism for inherited ventricular arrhythmias in German shepherd dogs. J Am Coll Cardiol. (1996) 27:1526-33. doi: 10.1016/0735-1097(95)00618-4

17. Burashnikov A, Antzelevitch C. Reinduction of atrial fibrillation immediately after termination of the arrhythmia is mediated by late phase 3 early afterdepolarization-induced triggered activity. Circulation (2003) 107:235560. doi: 10.1161/01.cir.0000065578.00869.7c

18. Patterson E, Jackman WM, Beckman KJ, Lazzara R, Lockwood D, Scherlag BJ, et al. Spontaneous pulmonary vein firing in man: relationship to tachycardia-pause early afterdepolarizations and triggered arrhythmia in canine pulmonary veins in vitro. J Cardiovas Electrophysiol. (2007) 18:106775. doi: 10.1111/j.1540-8167.2007.00909.x

19. Sato D, Xie LH, Sovari AA, Tran DX, Morita N, Xie F, et al. Synchronization of chaotic early afterdepolarizations in the genesis of cardiac arrhythmias. Proc Natl Acad Sci USA. (2009) 106:2983-8. doi: 10.1073/pnas.0809148106

20. Xie Y, Sato D, Garfinkel A, Qu Z, Weiss JN. So little source, so much sink: requirements for afterdepolarizations to propagate in tissue. Biophys J. (2010) 99:1408-15. doi: 10.1016/j.bpj.2010.06.042

21. Janse MJ, Wit AL. Electrophysiological mechanisms of ventricular arrhythmias resulting from myocardial ischemia and infarction. Physiol Rev. (1989) 69:1049-169. doi: 10.1152/physrev.1989.69.4.1049

22. RodrÍGuez B, Trayanova N, Noble D. Modeling cardiac ischemia. Ann N Y Acad Sci. (2006) 1080:395-414. doi: 10.1196/annals.1380.029

23. Antzelevitch C, Jalife J, Moe GK. Characteristics of reflection as a mechanism of reentrant arrhythmias and its relationship to parasystole. Circulation (1980) 61:182-91.

24. Antzelevitch C, Moe GK. Electrotonically mediated delayed conduction and reentry in relation to "slow responses" in mammalian ventricular conducting tissue. Circ Res. (1981) 49:1129-39.

25. Jalife J, Moe GK. Excitation, conduction, and reflection of impulses in isolated bovine and serum cardiac purkinje fibers. Circ Res. (1981) 49:233-47.

26. Antzelevitch C, Bernstein MJ, Feldman HN, Moe GK. Parasystole, reentry, and tachycardia: a canine preparation of cardiac arrhythmias occurring across inexcitable segments of tissue. Circulation (1983) 68:1101-15.

27. Rozanski GJ, Jalife J, Moe GK. Reflected reentry in nonhomogeneous ventricular muscle as a mechanism of cardiac arrhythmias. Circulation (1984) 69:163-73.

28. Lukas A, Antzelevitch C. Reflected reentry, delayed conduction, and electrotonic inhibition in segmentally depressed atrial tissues. Can J Physiol Pharmacol. (1989) 67:757-64.

29. Auerbach DS, Grz?da KR, Furspan PB, Sato PY, Mironov S, Jalife J. Structural heterogeneity promotes triggered activity, reflection and 
arrhythmogenesis in cardiomyocyte monolayers. J Physiol. (2011) 589:236381. doi: $10.1113 /$ jphysiol.2010.200576

30. Goldstein SS, Rall W. Changes of action potential shape and velocity for changing core conductor geometry. Biophys J. (1974) 14:731-57. doi: 10.1016/s0006-3495(74)85947-3

31. Cabo C, Barr RC. Reflection after delayed excitation in a computer model of a single fiber. Circ Res. (1992) 71:260-70.

32. Zhou Y, Bell J. Study of propagation along nonuniform excitable fibers. Math Biosci. (1994) 119:169-203.

33. Lewis TJ. The Effects of Nonexcitable Regions on Signal Propagation in ExcitableMedia: Propagation Failure and Reflection. Ph.D. Thesis, University of Utah, Salt Lake City, UT (1998).

34. Keener JP, Lewis TJ. Wave-block in excitable media due to regions of depressed excitability. SIAM J Appl Math. (2000) 61:293-316. doi: $10.1137 / \mathrm{s} 0036139998349298$

35. Cytrynbaum EN, Lewis TJ. A global bifurcation and the appearance of a onedimensional spiral wave in excitable media. SIAM J Appl Dynam Syst. (2009) 8:348-70. doi: 10.1137/080722254

36. Mahajan A, Sato D, Shiferaw Y, Baher A, Xie LH, Peralta R, et al. Modifying L-type calcium current kinetics: consequences for cardiac excitation and arrhythmia dynamics. Biophys J. (2008) 94:411-23. doi: 10.1529/biophysj.106.98590

37. Mahajan A, Shiferaw Y, Sato D, Baher A, Olcese R, Xie LH, et al. A rabbit ventricular action potential model replicating cardiac dynamics at rapid heart rates. Biophys J. (2008) 94:392-410. doi: 10.1529/biophysj.106.98160

38. Xie Y, Grandi E, Bers DM, Sato D. How does beta-adrenergic signalling affect the transitions from ventricular tachycardia to ventricular fibrillation? Europace (2014) 16:452-7. doi: 10.1093/europace/eut412

39. Qu Z, Garfinkel A. An advanced algorithm for solving partial differential equation in cardiac conduction. IEEE Trans Biomed Eng. (1999) 46:1166-8.

40. Xie Y, Izu LT, Bers DM, Sato D. Arrhythmogenic transient dynamics in cardiac myocytes. Biophys J. (2014) 106:1391-7. doi: 10.1016/j.bpj.2013.12.050

41. Tran DX, Sato D, Yochelis A, Weiss JN, Garfinkel A, Qu Z. Bifurcation and chaos in a model of cardiac early afterdepolarizations. Phys Rev Lett. (2009) 102:258103. doi: 10.1103/PhysRevLett.102.258103

42. Sato D, Xie LH, Nguyen TP, Weiss JN, Qu Z. Irregularly appearing early afterdepolarizations in cardiac myocytes: random fluctuations or dynamical chaos? Biophys J. (2010) 99:765-73. doi: 10.1016/j.bpj.2010.05.019

43. Schmidt A, Azevedo CF, Cheng A, Gupta SN, Bluemke DA, Foo TK, et al. Infarct tissue heterogeneity by magnetic resonance imaging identifies enhanced cardiac arrhythmia susceptibility in patients with left ventricular dysfunction. Circulation (2007) 115:2006-14. doi: 10.1161/circulationaha.106.653568

44. Bishop MJ, Connolly A, Plank G. Structural heterogeneity modulates effective refractory period: a mechanism of focal arrhythmia initiation. PLOS ONE (2014) 9:e109754. doi: 10.1371/journal.pone.0109754

45. Qu Z, Weiss JN. Mechanisms of ventricular arrhythmias: from molecular fluctuations to electrical turbulence. Annu Rev Physiol. (2015) 77:29-55. doi: 10.1146/annurev-physiol-021014-071622

46. Kazbanov IV, ten Tusscher KH, Panfilov AV. Effects of heterogeneous diffuse fibrosis on arrhythmia dynamics and mechanism. Sci Rep. (2016) 6:20835. doi: 10.1038/srep20835

47. Varela M, Colman MA, Hancox JC, Aslanidi OV. Atrial heterogeneity generates re-entrant substrate during atrial fibrillation and anti-arrhythmic drug action: mechanistic insights from canine atrial models. PLoS Comput Biol. (2016) 12:e1005245. doi: 10.1371/journal.pcbi.1005245

48. Edwards AG, Grandi E, Hake JE, Patel S, Li P, Miyamoto S, et al. Nonequilibrium reactivation of $\mathrm{Na}+$ current drives early afterdepolarizations in mouse ventricle. Circ Arrhythm Electrophysiol. (2014) 7:1205-13. doi: 10.1161/circep.113.001666

49. Weiss JN, Karma A, Shiferaw Y, Chen PS, Garfinkel A, Qu Z. From pulsus to pulseless: the saga of cardiac alternans. Circ Res. (2006) 98:1244-53. doi: 10.1161/01.RES.0000224540.97431.f0

50. Panfilov AV, Keener JP. Effects of high frequency stimulation on cardiac tissue with an inexcitable obstacle. J Theor Biol. (1993) 163:439-48. doi: 10.1006/jtbi.1993.1129

51. Spector PS, Habel N, Sobel BE, Bates JH. Emergence of complex behavior: an interactive model of cardiac excitation provides a powerful tool for understanding electric propagation. Circ Arrhythm Electrophysiol. (2011) 4:586-91. doi: 10.1161/circep.110.961524

52. Dawson SP, Keizer J, Pearson JE. Fire-diffuse-fire model of dynamics of intracellular calcium waves. Proc Natl Acad Sci USA. (1999) 96:6060-3.

53. Izu LT, Wier WG, Balke CW. Evolution of cardiac calcium waves from stochastic calcium sparks. Biophys J. (2001) 80:103-20. doi: 10.1016/s0006-3495(01)75998-x

54. Franzini-Armstrong C, Protasi F, Ramesh V. Shape, size, and distribution of $\mathrm{Ca} 2+$ release units and couplons in skeletal and cardiac muscles. Biophys J. (1999) 77:1528-39. doi: 10.1016/S0006-3495(99)77000-1

55. Soeller C, Crossman D, Gilbert R, Cannell MB. Analysis of ryanodine receptor clusters in rat and human cardiac myocytes. Proc Natl Acad Sci. USA. (2007) 104:14958-63. doi: 10.1073/pnas.0703016104

56. Baddeley D, Jayasinghe ID, Lam L, Rossberger S, Cannell MB, Soeller C. Optical single-channel resolution imaging of the ryanodine receptor distribution in rat cardiac myocytes. Proc Natl Acad Sci. USA. (2009) 106:22275-80. doi: 10.1073/pnas.0908971106

57. Soeller C, Jayasinghe ID, Li P, Holden AV, Cannell MB. Three-dimensional high-resolution imaging of cardiac proteins to construct models of intracellular Ca2 + signalling in rat ventricular myocytes. Exp Physiol. (2009) 94:496-508. doi: 10.1113/expphysiol.2008.043976

58. Galice S, Xie Y, Yang Y, Sato D, Bers DM. Size matters: ryanodine receptor cluster size affects arrhythmogenic sarcoplasmic reticulum calcium release. J Am Heart Assoc. (2018) 7:e008724. doi: 10.1161/jaha.118.0 08724

59. Sobie EA, Dilly KW, dos Santos Cruz J, Lederer WJ, Jafri MS. Termination of cardiac $\mathrm{Ca}(2+)$ sparks: an investigative mathematical model of calcium-induced calcium release. Biophys J. (2002) 83:59-78. doi: 10.1016/S0006-3495(02)75149-7

Conflict of Interest Statement: The authors declare that the research was conducted in the absence of any commercial or financial relationships that could be construed as a potential conflict of interest.

Copyright () $2018 \mathrm{Kim}$ and Sato. This is an open-access article distributed under the terms of the Creative Commons Attribution License (CC BY). The use, distribution or reproduction in other forums is permitted, provided the original author(s) and the copyright owner(s) are credited and that the original publication in this journal is cited, in accordance with accepted academic practice. No use, distribution or reproduction is permitted which does not comply with these terms. 